\title{
Genetic diversity and assessment of 23 microsatellite markers for parentage testing of Santa Inês hair sheep in Brazil
}

\author{
C.A. Souza ${ }^{1}$, S.R. Paiva ${ }^{1}$, C.M. McManus ${ }^{2,3}$, H.C. Azevedo ${ }^{4}$, \\ A.S. Mariante ${ }^{1}$ and D. Grattapaglia ${ }^{1}$ \\ ${ }^{1}$ EMBRAPA Recursos Genéticos e Biotecnologia, Brasília, DF, Brasil \\ ${ }^{2}$ Departamento de Zootecnia, Universidade Federal do Rio Grande do Sul, \\ Porto Alegre, RS, Brasil \\ ${ }^{3}$ Universidade de Brasília, Campus Darcy Ribeiro, Brasília, DF, Brasil \\ ${ }^{4}$ EMBRAPA Tabuleiros Costeiros, Aracaju, SE, Brasil \\ Corresponding author: S.R. Paiva \\ E-mail: samuel.paiva@embrapa.br
}

Genet. Mol. Res. 11 (2): 1217-1229 (2012)

Received September 26, 2011

Accepted November 28, 2011

Published May 8, 2012

DOI http://dx.doi.org/10.4238/2012.May.8.4

\begin{abstract}
Santa Inês is the most common hair sheep breed in Brazil and probably has the highest genetic diversity among sheep breeds in this country. Successful breeding programs for Brazilian sheep breeds are not common for various reasons, including a lack of control of parentage in the flocks. We developed an allele frequency database for 23 STR loci for the Santa Inês breed based on 285 animals sampled from five populations distributed across the central-western and north-eastern regions of Brazil. The marker set included seven microsatellites used in the 2011 International Society for Animal Genetics sheep genotyping comparison tests and all eight microsatellites currently approved by the Brazilian Agricultural Ministry laboratory accreditation guidelines for sheep identification. The microsatellites had an average of 10 alleles and a mean expected heterozygosity of 0.745 . Combined paternity exclusion probabilities when no parent or one parent was known were $>99.99 \%$. A small proportion
\end{abstract}


(5.8\%) of the existing genetic variation was found to be among the Santa Inês populations, possibly derived from genetic drift and selection. We found that the marker panel proposed by the Agricultural Ministry, although generally useful, should be enhanced by including more markers for improved exclusionary power in parentage testing. This database provides a useful tool for parentage testing of this major Brazilian breed, contributing to improved management and breeding of existing herds.

Key words: Animal Genetic Resources; Conservation and breeding programs; Genetic management; Molecular markers; Genetic diversity

\section{INTRODUCTION}

DNA-based animal parentage testing has become increasingly accessible and is now a routine technique in several advanced domestic animal breeding programs. Nevertheless, information on parent-offspring trios may still be unavailable or erratic, especially in low technology, extensive breeding operations such as those found to be common practice with sheep flocks in Brazil. The most common approach in these extensive animal breeding systems is the use of multiple-sire natural mating, so that only maternal control is carried out. Parentage inaccuracies may also occur in controlled systems due to human error when natural cross fostering is employed, with mislabeling of semen straws during artificial insemination operations, or when wrong animal identification codes are entered into the herd book (Weller et al., 2004). Under all such scenarios, DNA-based paternity testing provides a powerful tool to carry out precise breeding strategies and improve the overall quality of the flock.

Parental misidentification can reduce heritability estimates, while estimation of covariance interaction between fixed and random effects can also be affected (Senneke et al., 2004). Paternity misidentification has been shown to vary from 10 to $20 \%$ in breeding programs in developed countries (e.g., Banos et al., 2001; Visscher et al., 2002; Weller et al., 2004; Jiménez-Gamero et al., 2006) and was estimated to be over 35\% in Gyr cattle breeding in Brazil (Baron et al., 2002).

The certification of pedigrees using DNA markers is a viable option. Microsatellite markers are widely used in paternity testing because of their multiallelic nature, wide genome coverage and easy detection. Microsatellites are typically codominant with expected heterozygosity frequently greater than 0.7 , allowing precise discrimination of even closely related individuals. Due to the specificity of PCR assays and their high information content, they also allow the determination of identity between individuals based on formal estimates derived from allele frequencies.

The Brazilian Ministry of Agriculture, Livestock and Supply (MAPA) issued accreditation instructions in 2004 for laboratories that perform animal genetic identification using DNA fingerprinting. Eight microsatellite markers (OarCP49; OarFCB11; OarAE129; OarFCB304; MAF214; OMHC1; SPS113; D5S2) were suggested at the time for sheep and goat genotyping. No ISAG-recommended loci were yet available. These eight markers were chosen based on available information from the literature on microsatellites used for genotyping related species such as goats (Luikart et al., 1999), the relatively few reports for wool sheep breeds (Diez-Tascon et al., 2000; Farid et al., 2000; Arranz et al., 2001; Stahlberger-Saitbekova et al., 2001; Tomasco et al., 2002; Rychlik et al., 2003) and scant genotype data for some Brazilian animals. Currently, however, the majority of Brazilian animals belong to hair breeds, meaning 
that this set of markers may not be the best choice as far as information content for identity and parentage testing. In this study, we assessed the performance of these markers together with some recently ISAG-recommended microsatellites (Glowatzki-Mullis et al., 2007) for parentage identification in Santa Inês sheep, the breed with the largest population in Brazil and the highest genetic diversity among all breeds in the country (Paiva et al., 2005). Based on a sample of 285 animals from five Santa Inês populations, we built a representative database of allele frequencies for this breed and evaluated regional differences between the animals sampled across the country. Finally, the genetic data were used to propose an enhancement of the presently recommended MAPA marker panel to improve the current sheep genotyping guidelines in Brazil.

\section{MATERIAL AND METHODS}

\section{Animals}

Blood samples from 285 Santa Inês animals were collected from four small flocks sampled on private farms distributed along some Northeast region states and the Central-West region. A set of 21 unrelated animals were sampled from the State of Maranhão, 25 from Ceará, 17 from Sergipe, and 15 from the Federal District in Central-West Brazil, while all 207 animals from the EMBRAPA Conservation Nucleus farm in the State of Sergipe, irrespective of relatedness, were also studied. Genomic DNA was extracted and prepared according to a protocol described earlier (Paiva et al., 2005).

\section{Microsatellite genotyping}

In the present study, 23 microsatellite markers were used (Table 1). This set included eight of the 13 ISAG-recommended markers for the 2011 comparison test for sheep (ISAG, 2010) and all eight microsatellites proposed by the MAPA (2004). The MAPA-proposed 8-marker panel was compared to subsets of 15,10 , and 8 markers selected based on polymorphism information content (PIC) and probability of identity (PI) from the initial 23-marker set. The forward primer for each microsatellite was labeled with one fluorescent label: 6'FAM, HEX, TET, or NED (Applied Biosystems, USA). PCR amplification was as follows: initial denaturation at $95^{\circ} \mathrm{C}$ for $15 \mathrm{~min} ; 30$ cycles of denaturation at $94^{\circ} \mathrm{C}$ for $30 \mathrm{~s}$, annealing at $58^{\circ} \mathrm{C}$ for $90 \mathrm{~s}$, and elongation at $72^{\circ} \mathrm{C}$ for 60 $\mathrm{s}$, and a final elongation at $60^{\circ} \mathrm{C}$ for $30 \mathrm{~min}$, according to Glowatzki-Mullis et al. (2007). Alleles were resolved by capillary electrophoresis on an ABI3700 Genetic analyzer (Applied Biosystems). Genotypes were obtained using Gene Scan and Genotyper (Applied Biosystems).

\section{Data analysis}

Departure from Hardy-Weinberg expectations was estimated with GENEPOP 3.4 (Raymond and Rousset, 1995). The web-available softwares Cervus 3.0 (Kalinowski et al., 2007) and GenAlex (Peakall and Smouse, 2006) were used to estimate allele frequencies and basic diversity measures, as well as the power of the microsatellite panels for parentage testing using all 23 markers and the proposed subsets. Exclusion probability, combined exclusion probability, PI, expected $\left(H_{\mathrm{E}}\right)$ and observed $\left(H_{\mathrm{O}}\right)$ heterozygosities, and PIC were estimated. 
Table 1. Number of alleles per locus, heterozygosity measures, polymorphism information content, probabilities of paternity exclusion, probability of identity, test for Hardy-Weinberg equilibrium and inclusion of markers in each panel $(8,15$ or complete) in Santa Inês sheep.

\begin{tabular}{lrrrrrrrrrrrr}
\hline Locus & Alleles & Chromosome & $\mathrm{N}$ & $H_{\mathrm{O}}$ & $H_{\mathrm{E}}$ & $\mathrm{PIC}$ & $\mathrm{PE} 1$ & PE2 & PI & HWE & Selected \\
\hline BM6526 & 9 & 26 & 264 & 0.633 & 0.793 & 0.764 & 0.422 & 0.601 & 0.110 & $* *$ & 15 \\
BM827 & 8 & 3 & 233 & 0.627 & 0.662 & 0.636 & 0.274 & 0.462 & 0.130 & NS & \\
D5S2*\# & 9 & 5 & 278 & 0.543 & 0.815 & 0.787 & 0.454 & 0.630 & 0.480 & $* *$ & 8 \\
HUJ616 & 9 & 13 & 267 & 0.315 & 0.613 & 0.558 & 0.207 & 0.366 & 0.130 & $* *$ & \\
ILSTS05 & 11 & 7 & 268 & 0.739 & 0.835 & 0.812 & 0.494 & 0.666 & 0.110 & $* *$ & 8 \\
ILSTS11 & 8 & 9 & 276 & 0.710 & 0.723 & 0.677 & 0.310 & 0.485 & 0.096 & NS & 15 \\
ILSTS87 & 14 & 28 & 266 & 0.827 & 0.860 & 0.843 & 0.555 & 0.716 & 0.150 & NS & 8 \\
INRA172 & 15 & 14 & 261 & 0.636 & 0.691 & 0.652 & 0.290 & 0.469 & 0.220 & $* *$ & \\
INRA23 & 11 & 3 & 265 & 0.857 & 0.863 & 0.846 & 0.562 & 0.722 & 0.040 & NS & 8 \\
INRA35 & 8 & 16 & 271 & 0.764 & 0.807 & 0.78 & 0.446 & 0.624 & 0.057 & NS & 15 \\
INRA63 & 12 & 14 & 281 & 0.815 & 0.830 & 0.809 & 0.499 & 0.669 & 0.061 & NS & 8 \\
MAF214*\# & 5 & 16 & 275 & 0.531 & 0.469 & 0.397 & 0.110 & 0.222 & 0.320 & $* *$ & \\
MAF65 & 9 & 15 & 232 & 0.961 & 0.824 & 0.798 & 0.471 & 0.645 & 0.062 & $* *$ & 8 \\
OARAE129*\# & 8 & 5 & 266 & 0.459 & 0.660 & 0.602 & 0.238 & 0.400 & 0.250 & $* *$ & \\
OARCP20 & 8 & 21 & 281 & 0.584 & 0.668 & 0.635 & 0.271 & 0.455 & 0.330 & $* *$ & 15 \\
OARCP49 & *\# & 12 & 17 & 276 & 0.877 & 0.866 & 0.849 & 0.567 & 0.726 & 0.060 & NS & 8 \\
OARFCB11 $* \#$ & 8 & 2 & 254 & 0.740 & 0.784 & 0.750 & 0.402 & 0.581 & 0.076 & NS & 15 \\
OARFCB20 & 13 & 2 & 283 & 0.873 & 0.729 & 0.700 & 0.346 & 0.530 & 0.087 & $* *$ & \\
OARFCB304*\# & 16 & 19 & 262 & 0.740 & 0.786 & 0.757 & 0.422 & 0.599 & 0.120 & NS & 15 \\
OARHH35 & 12 & 4 & 257 & 0.732 & 0.846 & 0.827 & 0.527 & 0.693 & 0.055 & $* *$ & 8 \\
OMHC1*\# & 12 & 20 & 270 & 0.752 & 0.774 & 0.753 & 0.417 & 0.600 & 0.060 & NS & 15 \\
SPS113*\# & 9 & 10 & 274 & 0.500 & 0.566 & 0.541 & 0.189 & 0.369 & 0.150 & NS \\
SRCRSP05 & 4 & 21 & 253 & 0.609 & 0.675 & 0.603 & 0.232 & 0.384 & 0.170 & NS \\
Average & 10 & - & - & 0.688 & 0.745 & 0.712 & - & - & - &
\end{tabular}

*Markers proposed by the Ministry of Agriculture, Livestock and Supplies (MAPA) for parentage identification in sheep and goats. "Markers recommended by the International Society of Animal Genetics (ISAG). $\mathrm{N}=$ number of samples; $H_{\mathrm{O}}=$ observed heterozygosity; $H_{\mathrm{E}}=$ expected heterozygosity; $\mathrm{PIC}=$ polymorphism information content; PE1 and PE2 = cumulative parentage exclusion probability knowing one (PE1) or both (PE2) parents; PI = probability of identity; HWE = significance of the test for Hardy-Weinberg equilibrium; Selected = markers selected from the panel of 23 of the present study using 8 or 15 top markers for PIC and PI in Santa Ines breed. All markers from the 8 panel belong to the 15 panel. **HWE deviation; NS = nonsignificant.

The exclusion power (PE) when both parents are available was calculated using the formula of Jamieson and Taylor (1997):

$$
P E=1+4 \sum_{i=1}^{n} P_{i}^{4}-4 \sum_{i=1}^{n} P_{i}^{5}-3 \sum_{i=1}^{n} P_{i}^{6}-8\left(\sum_{i=1}^{n} P_{i}^{2}\right)^{2}+8\left(\sum_{i=1}^{n} P_{i}^{2}\right)^{0}\left(\sum_{i=1}^{n} P_{i}^{3}\right)+2\left(\sum_{i=1}^{n} P_{i}^{3}\right)^{2}
$$

After calculation of PE for each locus individually, a combined PE over $n$ independent markers was calculated using the following formula: $\mathrm{PE}=1-\left(1-\mathrm{P}_{1}\right)\left(1-\mathrm{P}_{2}\right)\left(1-\mathrm{P}_{3}\right) \ldots\left(1-\mathrm{P}_{\mathrm{n}}\right)$ (Jamieson and Taylor, 1997).

Analysis of molecular variance (AMOVA), implemented with GENALEX 6 (Peakall and Smouse, 2006), was used to assess genetic differentiation among the Santa Inês population samples. In addition, a dendrogram was drawn based on Nei's genetic distances, neighbor-joining clustering and bootstrap using the Dispan software (Ota, 1993).

\section{RESULTS}

Considerable variation was observed in the number of alleles across the $23 \mathrm{mi}$ - 
crosatellites, with an average of 10 alleles per locus, ranging from 4 (SRCRSP05) to 16 (OARFCB304). Of the 23 loci, 11 deviated from Hardy-Weinberg equilibrium, most of them due to a deficit of heterozygous individuals with the exception of MAF214, MAF65 and OarFCB20, which displayed excess $H_{\mathrm{O}}$ (Table 1).

Average PIC and $H_{\mathrm{E}}$ estimates were respectively 0.712 and $0.745 . H_{\mathrm{O}}$ ranged from a low of 0.315 for HUJ616 to the highest value of 0.961 for MAF65, while $H_{\mathrm{E}}$ ranged from 0.469 (MAF214) to 0.866 (OARCP49). PIC ranged from 0.397 (MAF214) to 0.849 (OARCP49). The mean PIC for MAPA-recommended microsatellites was 0.6795 while the highest PIC was 0.8214 (Table 2). As expected from theory, estimates of probability of identity were highly correlated to PIC values. The cumulative probabilities of paternity exclusion, with none or one parent is known (PE1 and PE2, respectively), were 99.9999 and 99.9989\%, respectively, when all 23 markers were used and decreased to 99.708 and $99.799 \%$, respectively, when only the MAPA-recommended markers were used. The complete database of allele frequencies for all 23 microsatellite markers surveyed is provided as Supplementary material.

Table 2. Combined estimates of probability of identity and probabilities of exclusion for different microsatellite
panels in Santa Inês sheep.
\begin{tabular}{lccc}
\hline \# Marker set & PI & PE1 (\%) & PE2 (\%) \\
\hline All 23 markers & $4.2 \mathrm{E}-25$ & 99.999 & 99.999 \\
15 with the highest PI value & $3.3 \mathrm{E}-19$ & 99.992 & 99.999 \\
13 with the highest PI value & $2.7 \mathrm{E}-17$ & 99.981 & 99.999 \\
10 with the highest PI value & $6.4 \mathrm{E}-14$ & 99.907 & 99.999 \\
8 with the highest PI value & $1.4 \mathrm{E}-11$ & 99.708 & 99.990 \\
8 proposed by MAPA & $1.1 \mathrm{E}-8$ & 97.378 & 99.799 \\
\hline PI = probability of identity; PE1 and PE2 = combined probability of parentage exclusion knowing one (PE1) or
\end{tabular}
both (PE2) parents; MAPA = Ministry of Agriculture, Livestock and Supplies.

Examining the diversity between populations (Table 3), the average number of alleles within each region was lower than the overall mean (6.78), suggesting the occurrence of genetic drift and lower within-region variation. Observed and expected heterozygosities were similar across regions. Estimates of $F_{\text {IS }}$ were not significantly different from zero for the small flocks, while the EMBRAPA flock, with a larger number of individuals and thus providing more power for the tests, showed significant inbreeding. AMOVA revealed that a small (5.8\%) although significant $(\mathrm{P}<0.001)$ proportion of the existing genetic variation was due to differences between the Santa Inês populations corroborating the occurrence of genetic drift.

Table 3. Within genetic diversity in five Santa Inês flocks analyzed in Brazil.

\begin{tabular}{lccccc}
\hline Flock & $\mathrm{N}$ & $N_{\text {AM }}$ & $H_{\mathrm{O}}$ & $H_{\mathrm{E}}$ & $F_{\text {IS }}$ \\
\hline CW & 15 & 5.65 & 0.79 & 0.70 & 0.028 \\
SE & 17 & 6.53 & 0.74 & 0.71 & 0.045 \\
EM & 207 & 9.19 & 0.72 & 0.69 & $0.053^{*}$ \\
MA & 21 & 6.61 & 0.79 & 0.66 & 0.092 \\
CE & 25 & 5.92 & 0.72 & 0.71 & 0.025 \\
\hline
\end{tabular}

$* \mathrm{P}<0.05$ adjusted by the Bonferroni test; $\mathrm{CW}=$ Central-West region; $\mathrm{SE}=$ Sergipe State; $\mathrm{EM}=$ Embrapa Conservation Nucleus; MA = Maranhão State; $\mathrm{CE}=$ Ceará State. $\mathrm{N}=$ Number of samples; $N_{\mathrm{AM}}=$ average number of alleles; $H_{\mathrm{O}}=$ observed heterozygosity, $H_{\mathrm{E}}=$ expected heterozygosity; $F_{\mathrm{IS}}=$ inbreeding coefficient. 
The dendrogram based on genetic distances indicated a closer relationship between animals in the Central-West region and Sergipe, and the uniqueness of the EMBRAPA conservation flock (Figure 1).

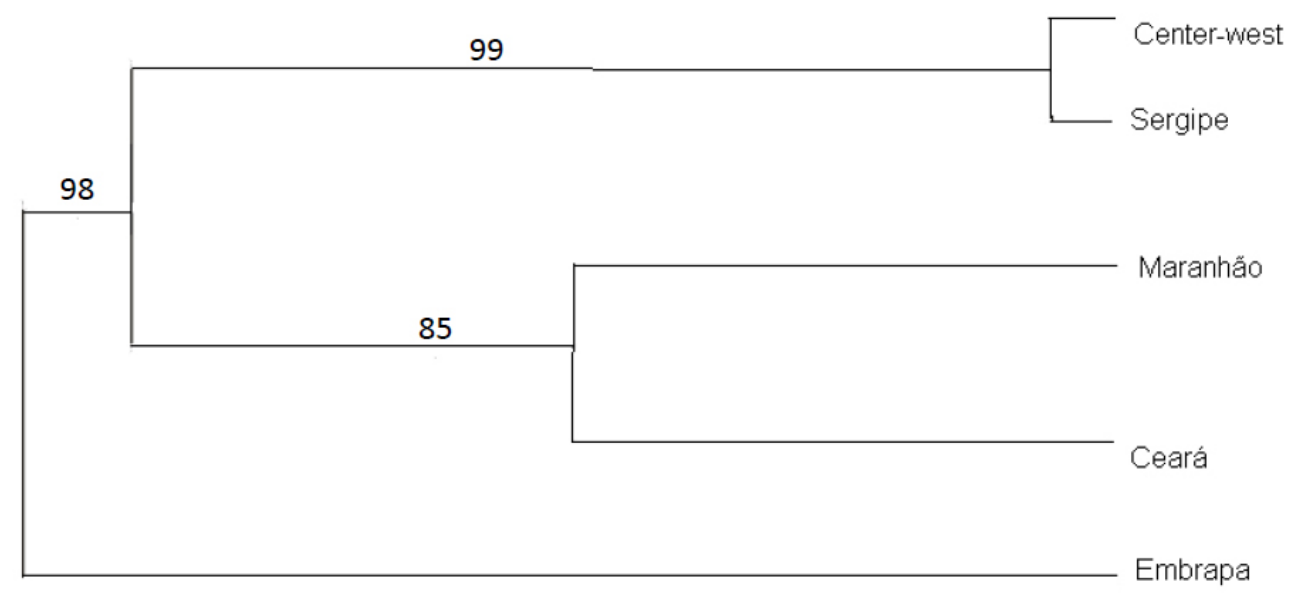

Figure 1. Dendrogram of distances between flocks of Santa Inês sheep in Brazil. Bootstrap values are shown for values above $50 \%$.

\section{DISCUSSION}

In 2004, the MAPA issued laboratory accreditation guidelines for animal genotyping services in Brazil. At that time, while microsatellite marker panels were relatively well established and validated worldwide by ISAG for horse and bovine genotyping, this was not yet the case for goats and sheep. Different markers had been used by different laboratories and no ISAG standard set was available. Nevertheless, the objective of providing initial genotyping guidelines for these animal species was achieved by proposing an eight-marker set based on what the literature provided at the time for wool sheep breeds and on preliminary genotype data obtained for a few animals from local breeds. In this study, we revisited this subject with a 3-fold objective: 1) to provide a comprehensive database of allele frequencies for a large number of microsatellite markers for Santa Inês, the most widely raised sheep breed in the country; 2) to compare some of the most recently ISAG-recommended markers with the marker set currently in use in Brazil, and 3) to provide a first glance at the regional genetic diversity of existing Santa Inês sheep flocks.

\section{Microsatellite markers}

In the Santa Inês populations surveyed, not only all 23 markers were polymorphic (Table 1), but the average number of alleles per marker (10) was considerably higher than that found in sheep populations in Bhutan (Dorji et al., 2010) and Iran (Saberivand et al., 2010), as well as North American and British breeds (Farid et al., 2000). Glowatzki-Mullis et al. (2007) analyzed 10 diverse breeds with a 19-microsatellite multiplex and found an average maximum of 7.79 
alleles for Red Engadin sheep, while Baumung et al. (2006) reported an average of 15 alleles per locus when 25 microsatellite markers were surveyed in 717 animals of 11 Austrian breeds. Although estimates of average numbers of alleles will vary with the specific markers employed and possibly with the accuracy of the genotyping system used, our results indicate that the Santa Inês breed in fact displays relatively high levels of genetic diversity, as expected at the onset of this study.

The overall estimate of average $H_{\mathrm{O}}(0.688)$ was lower than the $H_{\mathrm{E}}(0.745)$ under equilibrium when all 23 microsatellites were taken together. With 11 markers, a significant departure from Hardy-Weinberg proportions was detected (Table 1). While such deviations could be due to the possible occurrence of null alleles at some loci, they are most likely derived from some level of non-random mating due to the preferential use of specific rams, coupled to a reduction of heterozygosity expected due to genetic drift, as five different populations with unbalanced sample sizes were analyzed jointly to reach these estimates (see below). Three of the eight MAPA-proposed markers and four of the seven recommended by ISAG showed deviations from HWE. Despite these deviations, there seems to be no major issue with any of these 23 microsatellite markers, taken individually, to preclude their potential use for adequate genotyping of Santa Inês animals. The issue remains of selecting those that provide the highest information content for individual identification and parentage testing.

The probability of paternity exclusion estimates the power that the marker provides for excluding a non-parent from paternity or maternity. This parameter was estimated for two common scenarios in Santa Inês breeding, i.e., when no parent (PE1) or one parent is known (PE2) when testing parentage. Overall, the probabilities were high to moderate for all the microsatellites analyzed, with PE2 ranging from 0.222 for the least powerful marker, MAF214, to 0.726 for OARCP 49 , the most informative one (Table 1). These estimates are generally higher than the estimates reported for 19 microsatellites by Glowatzki-Mullis et al. (2007) when data on 316 sheep from 10 breeds were jointly analyzed resulting in a range of PE2 from 0.073 to 0.573. Eight markers were used in both studies (ILST011, ILST005, INRA63, MAF65, OarCP49, OarFCB20, OarFCB304, and SPS113), allowing a direct comparison. For all these markers except OarFCB20, the estimates of probability of paternity exclusion were higher in Santa Inês than the estimates reported for the above-mentioned 10 breeds.

Combined probabilities of paternity exclusion were estimated for different marker panels starting with the full set of 23 markers tested and subsets of smaller number of markers selected based on the highest PI (Table 3). When one parent was known, all marker panels, except that proposed by MAPA, provide a combined probability $\geq 99.99 \%$, which is generally considered an adequate threshold for most breeding applications. This result shows that the current MAPA marker set, while still providing relatively good power for paternity exclusion, can be improved with the addition or substitution of markers. In this respect, the data gathered in this study provide a useful starting point to recommend specific markers that would provide additional power for fingerprinting and parentage in this widely distributed Brazilian breed and, at the same time, be part of the currently recommended ISAG markers for sheep genotyping at the international level. Currently, only two MAPA-proposed markers are part of the 13 marker panel recently recommended by ISAG, markers D5S2 and SPS113. A straightforward recommendation would be to add markers INRA172, INRA23, INRA63, MAF65, and OarFBC20, which are part of the ISAG panel to the MAPA 8-marker set, therefore, totaling 13 markers, which would provide an overlap of seven markers with the ISAG set and eight 
markers with previous sheep genotyping carried out in Brazil.

While the combined estimate of probability of exclusion is a generally useful parameter, it is important to point out that it assumes random mating and no relatedness between the alleged parent tested and the true parent. In the current sheep breeding scenarios in Brazil, it is common for related rams (half-sibs or even full-sibs) to be used in open-field multiple-sire breeding schemes. Therefore, for precise paternity determination in such situations, it is probably sensible to use an excess of prior power of exclusion to protect against false-paternity inclusions, i.e., declaring a ram as father when in fact its half-sib or full-sib is the true father. Our results show that in practice, a panel of 10 to 15 markers will provide adequate prior power of exclusion in the Santa Inês breed. However, in special cases, when additional prior evidence exists to consider two alternative related rams as putative fathers, a larger microsatellite panel, with all 23 markers, should be used providing a prior PE in excess of $99.999 \%$. Concerning the combined estimates of probability of identity, any marker panel would provide fully satisfactory ability to discriminate animals or validate the identity of clonal individuals when such a test is demanded.

\section{Genetic diversity in Santa Inês breed}

Besides an assessment of the performance of microsatellite marker panels used to date for sheep genotyping, the data assembled provide a first glimpse at the distribution of genetic variation for this sheep breed among four different flocks sampled in different regions in Brazil and a larger flock that constitutes a germplasm conservation nucleus. Despite the quite unbalanced sample size, the results show that all the four flocks displayed a relatively high and homogeneous heterozygosity, similar average allele number and no significant inbreeding (Table 3). The EMBRAPA animal germplasm collection with a much larger sample had almost twice the average number of alleles at the 23 microsatellites typed and displayed a small, although significant, inbreeding. While the larger sample size provided higher power to detect deviations from HWE when compared to the four small flocks sampled, the level of inbreeding detected was expected due to the inclusion of genetically related individuals in the sample, derived from the recurrent use of a small number of rams in an extensive breeding system. This result calls for a greater attention in the management of the EMBRAPA sheep germplasm collection and its potential use in breeding practice. As many as possible unrelated or newly introduced rams should be used in the flock in order to maintain and enrich the genetic base of the collection through future offspring.

Results of AMOVA are in agreement with the expectations. Very little, although significant, variation (5.8\%) was found among the four flocks and the EMBRAPA conservation nucleus, most likely as a result of genetic drift and some level of selection. Most of the genetic diversity was found within the groups, with the EMBRAPA collection contributing the largest proportion of the variation as a result of the largest sample size. The flocks from Federal District and Sergipe were closely related in the dendrogram plot. This was expected, as most animals in the Federal District were imported from Sergipe due to a lack of Federal sanitary barrier between these States and the action of a strong association of breeders. The type of animal found in both regions is morphologically similar and different from animals found in other places in the Northeast region, as recently reported with morphometric markers (Carneiro et al., 2010). These cited authors noted that the pattern is consistent with the hypothesis for the existence of an "Old Santa Inês" breed versus the "New Santa Inês". Breeders and technicians classify the Old Santa Inês as smaller more rustic animals, which were predominant in the 
1980s and 1990s. The New Santa Inês, probably originating in Sergipe, are more prevalent in populations of the Central-West and Southeast regions. They have a large, well-developed rump and largely black or brown pelts, which has appeared in a large proportion of the population in the last few years. This has led to reduced heat tolerance (McManus et al., 2009a) and resistance to endoparasites (McManus et al., 2009b). In addition, according to records of these flocks, the morphological changes that led to the creation of a New Santa Inês were possibly intensified by the introduction, from time to time, of some rams during mating season in order to increase the fertility of the flocks.

\section{Conclusions and recommendations}

The allelic frequency database reported in this study can be immediately used in parentage testing practice and sheep breed registers of Santa Inês animals across accredited Brazilian laboratories. The results of this study suggest that the MAPA-proposed marker panel, although generally useful, can and should be enhanced by including more markers, thus supplying improved exclusionary power, especially in the presence of deficient parentage testing. While the addition of new markers seems to be an urgent matter, a general consensus based on reliable genetic data derived from nationwide studies of the most relevant breeds should follow. Recommendations coming from ISAG comparison tests should also be taken into account in spite of the still undefined status of an internationally agreed sheep genotyping microsatellite panel and the fact that such recommendations typically come from studies with wool sheep breeds.

A more definitive marker panel should therefore contemplate several issues and be valid for all other sheep breeds raised in Brazil. Based on the existing literature and the recent ISAG comparison tests, it is likely that all 23 microsatellites will also provide adequate power to carry out genotyping in most, if not all, other sheep breeds, although specific surveys would be necessary to validate this claim. In practice, however, for the time being, a reasonable proposal to move ahead from the existing scenario would be to add some five to seven ISAGvalidated markers to the MAPA set, thus totaling 13 to 15 markers. This improved set would provide a rational compromise between the already genotyped animals while abiding with a final international set to be recommended by ISAG. Such a unified microsatellite marker panel would increase the confidence of the Brazilian breeder community in registering their animals, improve the reliability of national reports and help direct future breeding and conservation programs. In the meantime, the feasibility of moving from microsatellite- to SNP-based genotyping for sheep will receive greater attention and could become the system of choice for the future, provided a drop in infra-structure costs takes place and that a sensible solution is presented to update the DNA profiles of already genotyped animals.

\section{ACKNOWLEDGMENTS}

Research supported by CNPq, INCT-Pecuária, FAPDF, and EMBRAPA.

\section{REFERENCES}

Arranz JJ, Bayón Y and San Primitivo F (2001). Differentiation among Spanish sheep breeds using microsatellites. Genet.
Sel. Evol. 33: 529-542.
Banos G, Wiggans GR and Powell RL (2001). Impact of paternity errors in cow identification on genetic evaluations and 
international comparisons. J. Dairy Sci. 84: 2523-2529.

Baron EE, Martinez ML, Verneque RS and Coutinho LL (2002). Parentage testing and effect of misidentification on the estimation of breeding value in Gir cattle. Genet. Mol. Biol. 25: 389-394.

Baumung R, Cubric-Curik V, Schwend K, Achmann R, et al. (2006). Genetic characterisation and breed assignment in Austrian sheep breeds using microsatellite marker information. J. Anim. Breed. Genet. 123: 265-271.

Carneiro H, Louvandini H, Paiva SR, Macedo F, et al. (2010). Morphological characterization of sheep breeds in Brazil, Uruguay and Colombia. Small Rum. Res. 94: 58-65.

Diez-Tascon C, Littlejohn RP, Almeida PA and Crawford AM (2000). Genetic variation within the Merino sheep breed: analysis of closely related populations using microsatellites. Anim. Genet. 31: 243-251.

Dorji T, Jianlin H, Wafula P, Yamamoto Y, et al. (2010). Sheep genetic diversity in Bhutan using microsatellite markers. Anim. Sci. J. 81: 145-151.

Farid A, O'Reilly E, Dollard C and Kelsey CR Jr (2000). Genetic analysis of ten sheep breeds using microsatellite markers. Can. J. Anim. Sci. 80: 9-17.

Glowatzki-Mullis ML, Muntwyler J and Gaillard C (2007). Cost-effective parentage verification with 17-plex PCR for goats and 19-plex PCR for sheep. Anim. Genet. 38: 86-88.

ISAG (2010). Applied Genetics in Sheep and Goats Workshop. In: 32th International Conference on Animal Genetics. Available at [www.isag.us/Docs/Applied_GeneticsSheepGoats_CT.pdf]. ISAG, Edinburgh. Accessed April, 2011.

Jamieson A and Taylor SCS (1997). Comparison of three probability formulae for parentage exclusion. Anim. Genet. 28: 397-400.

Jiménez-Gamero I, Dorado G, Muñoz-Serrano A, Analla M, et al. (2006). DNA microsatellites to ascertain pedigreerecorded information in a selecting nucleus of Murciano-Granadina dairy goats. Small Rum. Res. 65: 266-273.

Kalinowski ST, Taper ML and Marshall TC (2007). Revising how the computer program CERVUS accommodates genotyping error increases success in paternity assignment. Mol. Ecol. 16: 1099-1106.

Luikart G, Biju-Duval MP, Ertugrul O, Zagdsuren Y, et al. (1999). Power of 22 microsatellite markers in fluorescent multiplexes for parentage testing in goats (Capra hircus). Anim. Genet. 30: 431-438.

MAPA (2004). Instrução Normativa No. 74 de 20 de Outubro de 2004. Ministério da Agricultura, Pecuária e Abastecimento, Brasília.

McManus C, Paludo GR, Louvandini H, Gugel R, et al. (2009a). Heat tolerance in Brazilian sheep: physiological and blood parameters. Trop. Anim. Health Prod. 41: 95-101.

McManus C, Louvandini H, Paiva SR, de Oliveira AA, et al. (2009b). Genetic factors of sheep affecting gastrointestinal parasite infections in the Distrito Federal, Brazil. Vet. Parasitol. 166: 308-313.

Ota T (1993). DISPAN: Genetic Distance and Phylogenetic Analysis University Park: Institute of Molecular and Evolutionary Genetics. The Pennsylvania State University, Pennsylvania.

Paiva SR, Silvério VC, Egito AA, Pimentel CMM, et al. (2005). Genetic variability of the Brazilian hair sheep breeds. Pesq. Agropec. Bras. 40: 887-893.

Peakall R and Smouse PE (2006). GenAlEx 6: genetic analysis in Excel. Population genetic software for teaching and research. Mol. Ecol. Notes. 6: 288-295.

Raymond M and Rousset F (1995). Population Genetics Software for Exact Tests and Ecumenicism. J. Hered. 86: 248249.

Rychlik T, Radko A and Duniec M (2003). Evaluating the usefulness of polymorphism of some genetic markers for parentage control of sheep. Med. Weterynaryjna 59: 1016-1018.

Saberivand A, Mohammadi G and Javanmard A (2010). Genetic variation of ten microsatellite loci in Makui sheep of Iran. Vet. Res. Commun. 34: 541-548.

Senneke SL, MacNeil MD and Van Vleck LD (2004). Effects of sire misidentification on estimates of genetic parameters for birth and weaning weights in Hereford cattle. J. Anim. Sci. 82: 2307-2312.

Stahlberger-Saitbekova N, Schläpfer J, Dolf G and Gaillard C (2001). Genetic relationships in Swiss sheep breeds based on microsatellite analysis. J. Anim. Breed. Genet. 118: 379-387.

Tomasco I, Wlasiuk G and Lessa EP (2002). Evaluation of polymorphism in ten microsatellite loci in Uruguayan sheep flocks. Genet. Mol. Biol. 25: 37-41.

Visscher PM, Woolliams JA, Smith D and Williams JL (2002). Estimation of pedigree errors in the UK dairy population using microsatellite markers and the impact on selection. J. Dairy Sci. 85: 2368-2375.

Weller JI, Feldmesser E, Golik M, Tager-Cohen I, et al. (2004). Factors affecting incorrect paternity assignment in the Israeli Holstein population. J. Dairy Sci. 87: 2627-2640. 
Parentage testing in Santa Inês sheep

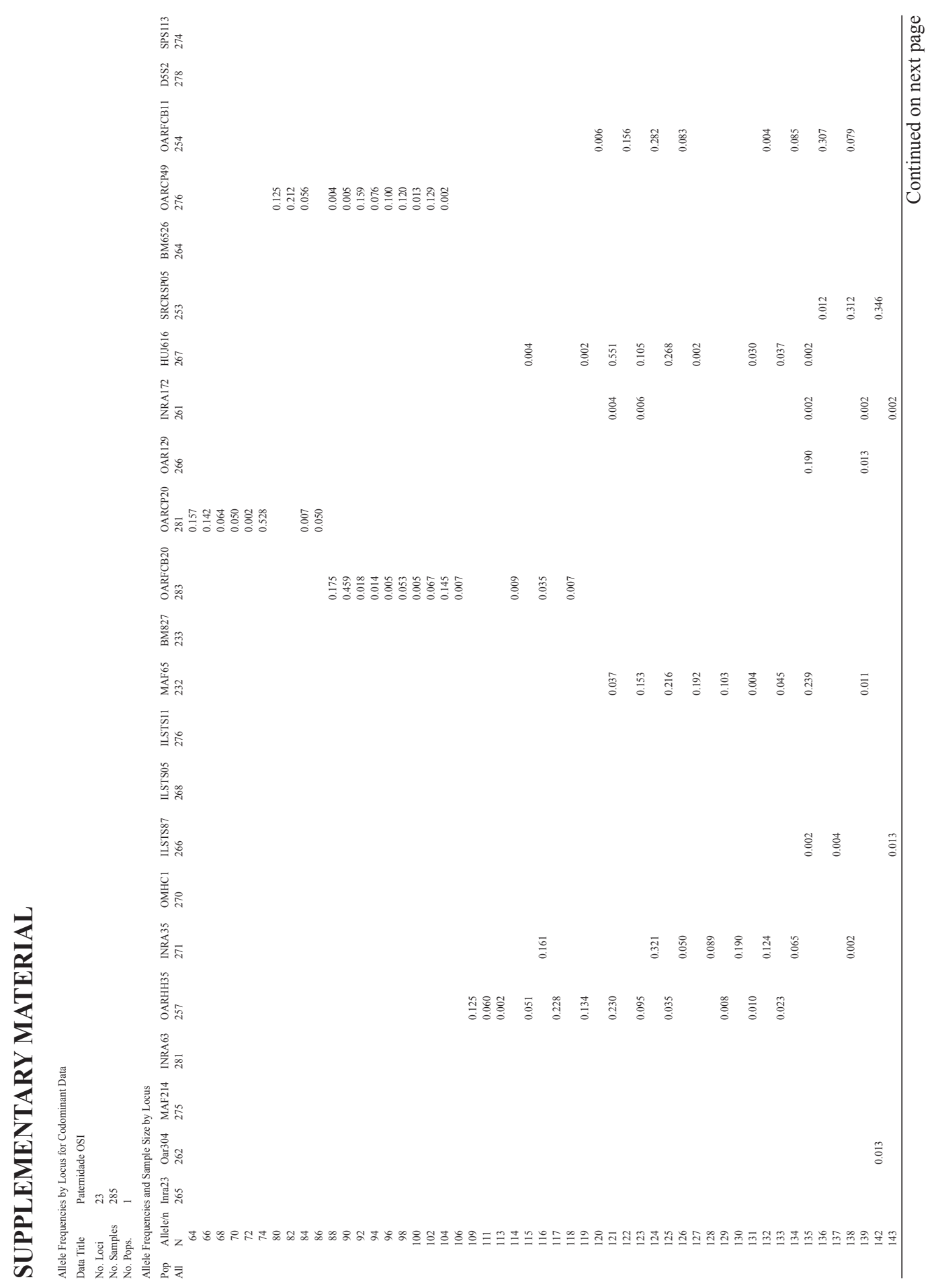

Genetics and Molecular Research 11 (2): 1217-1229 (2012) 


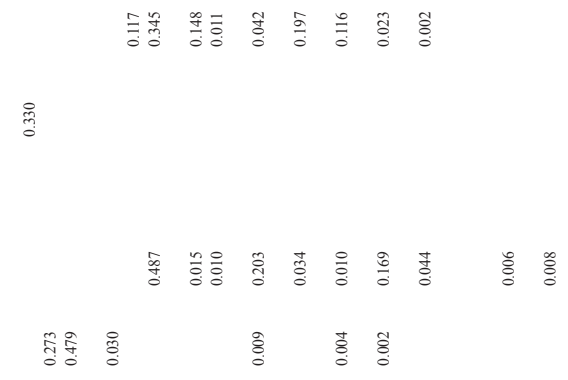




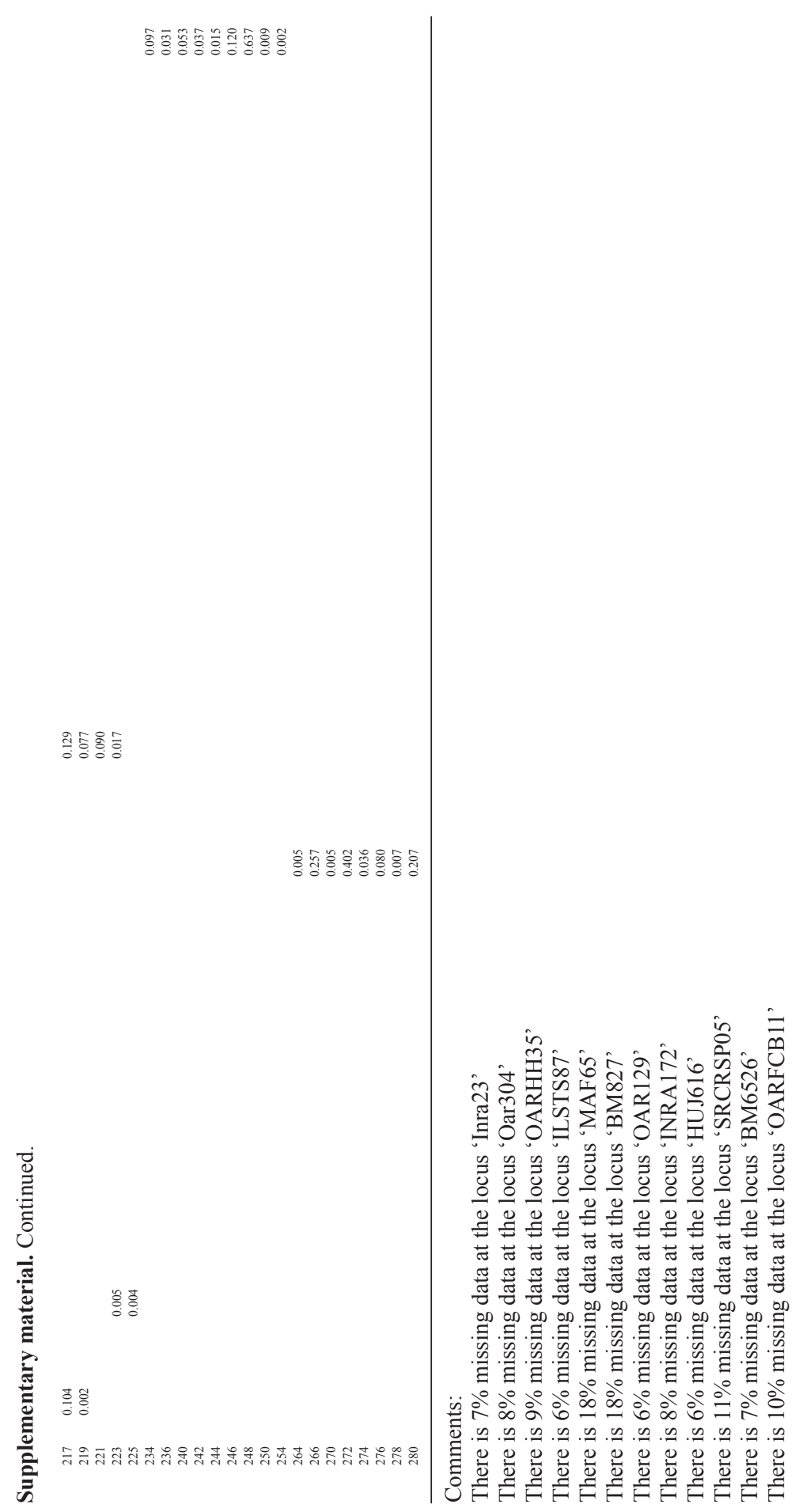

